\title{
Ensinando e Aprendendo Geometria Plana Através de Vídeo Educativo: Algumas Sugestões de Atividades Didáticas para Aulas de Matemática no Ensino Médio
}

Marcos Pereira dos Santos

\begin{abstract}
Resumo
Este artigo tem como principal objetivo apresentar algumas sugestões de atividades didáticas que podem ser realizadas pelos professores de matemática do ensino médio na abordagem de conteúdos de geometria plana, a partir da exibição do vídeo educativo intitulado Nas malhas da geometria. Para tanto, inicialmente são fornecidas breves informações técnico-descritivas sobre o vídeo em questão para uso em sala de aula. Em seguida, sugerimos alguns encaminhamentos para exploração didática do vídeo educativo supracitado em aulas de matemática no ensino médio, especificamente no que se refere ao desenvolvimento de trabalhos pedagógicos interdisciplinares, à realização de estudos temáticos específicos de geometria plana e à proposição de atividades didáticas complementares visando à construção do pensamento geométrico.
\end{abstract}

Palavras-chave: Geometria plana. Vídeo educativo. Recurso audiovisual. Ensino médio.

\section{Abstract}

Teaching and Learning Plane Geometry Through Educational Video: Some Suggestions for Didactics Activities for Math Classes in High School

This article has as main objective to present some suggestions for didactics activities that can performed by high school math teachers in content approach of plane geometry, from the display of the educational video title On geometry meshes. To do so, are provided technical-descriptive short information initially about the video in question for use in the classroom. Then we suggest some referrals to didactic exploration of that educational video math lessons by high school, specifically with regard to the development of interdisciplinary works pedagogics, the realization of specific thematic studies of plane geometry and the proposition of complementary didactics activities aiming at the construction of geometric thinking.

Keywords: Plane geometry. Educational video. Audiovisual resource. High school.

\section{Introdução}

Em plena era da Informática, das viagens espaciais e das minicalculadoras portáteis, o ensino da Matemática escolar já não pode ser o mesmo de épocas passadas. Muitos adultos de hoje estão em verdadeiro "pé de guerra" com a Matemática por causa de um ensino "deficiente" que, na escola tradicional de décadas anteriores ao século XXI, por exemplo, se limitava 
praticamente ao aprendizado de regras de cálculo e memorização de fórmulas e definições matemáticas.

No caso do ensino da aritmética, álgebra, estatística e geometria a situação também não é diferente, embora a Matemática tenha como finalidade precípua possibilitar aos alunos uma leitura crítica do mundo, instrumentalizando-os para uma análise cuidadosa da realidade objetiva existencial concreta, de maneira que seja utilizada como instrumento de emancipação e não de dominação (D’AMBRÓSIO, 1986).

Nesse sentido, o presente artigo busca apresentar algumas sugestões de atividades didáticas que podem ser realizadas pelos professores de matemática do ensino médio na abordagem de conteúdos de geometria plana, a partir da exibição do vídeo educativo intitulado Nas malhas da geometria.

Sendo assim, almejamos que os apontamentos trazidos a lume possam, efetivamente, contribuir para a ampliação do arcabouço teórico existente no campo da Educação Matemática e da Educação Geométrica, bem como servir de subsídio didático-pedagógico e metodológico para educadores matemáticos, professores de matemática, pedagogos escolares e demais profissionais das áreas de Ciências Exatas e Artes Plásticas que se utilizam, direta ou indiretamente, de conhecimentos matemático-geométricos para o desenvolvimento de suas atividades laborais.

\section{Luz, câmera, ação ... : breves informações técnico- descritivas sobre o vídeo educativo Nas malhas da geometria para uso em sala de aula}

"Vendo e aprendendo", além de ser o nome do título de uma série de programas desenvolvidos pela TV Escola, é também uma expressão adequada para destacar a importância do professor em fazer uso de vídeos educativos na escola, principalmente em aulas de Matemática e, particularmente, no ensino de geometria plana. Dizemos isso, porque corroboramos com Fonseca et al (2001, p.117-118) ao afirmar que os vídeos educativos, no caso específico de estudo de geometria, tem como função precípua:

"[...] provocar uma reflexão e uma discussão a respeito da presença da geometria nas diversas situações de nossa vida pessoal e/ou profissional e da necessidade de se estudá-la na escola para desenvolver competências que atendam às demandas forjadas em tais situações. A importância da Educação Matemática na formação dos cidadãos vem sendo geralmente reconhecida, $e$, em particular, a Educação Geométrica tem sido apontada como possibilitadora do desenvolvimento de habilidades e competências essenciais a essa formação. [...] Trata-se de olhar a geometria para além de sua dimensão como conteúdo escolar - vê-la como experiência dos homens desde a pré-história, processo e 
produto de suas necessidades materiais e de seu pensamento. Ao lado da aritmética, frequentemente privilegiada na prática das salas de aula da Educação Fundamental brasileira, a geometria é uma das raízes da Matemática como campo científico, e, ao mesmo tempo, um conhecimento básico do patrimônio cultural de todos os grupos humanos."

Partindo desse pressuposto, consideramos ser o vídeo educativo intitulado Nas malhas da geometria um excelente recurso audiovisual para o trabalho com alguns tópicos de geometria plana no ensino médio, o qual pode ser facilmente encontrado em videotecas escolares e locadoras de filmes comerciais.

A exibição do vídeo tem a duração total de 12'45" e faz parte do rol de programas educativos produzidos pela TV Escola - "Série Mão na Forma", no ano de 2000, em convênio com a Secretaria de Educação a Distância do Ministério da Educação (MEC).

Em tese, a sinopse do vídeo em questão é a seguinte: Norma (personagem fictício) revela o seu fascínio pelas formas complexas das criaturas marinhas e se mostra totalmente cética sobre a possibilidade de que existam padrões geométricos nas mesmas. Pensando nas relações entre geometria e Natureza, Norma faz um passeio por algumas obras de arte moderna e contemporânea. Mais tarde, ela descobre, enfim, que é possível construir malhas complexas a partir de formas geométricas bastante simples (BRASIL, 2000).

De modo geral, o vídeo educativo Nas malhas da geometria destaca a importância dos professores de matemática, ao abordarem os conteúdos curriculares de geometria plana na escola de ensino médio, darem maior ênfase às atividades didáticas que relacionam os objetos geométricos com os do mundo real do que à memorização de nomes de figuras isoladas de contextos. Além disso, o vídeo em questão exibe imagens de padrões geométricos na Natureza e mostra, por meio de efeitos especiais, a estrutura de triângulos em um telhado; apresentando ainda entrevistas com diferentes profissionais (arquitetos, engenheiros civis, artistas plásticos, historiadores, biólogos entre outros) que se utilizam da Matemática e, em específico, da geometria plana em suas respectivas áreas de atuação.

\section{Para além do som e das imagens: algumas sugestões de encaminhamentos para exploração didática do vídeo educativo Nas malhas da geometria em aulas de matemática no ensino médio}

\subsection{Desenvolvimento de trabalhos pedagógicos interdisciplinares}


O vídeo educativo é um dos grandes recursos da interdisciplinaridade, uma vez que possibilita a fusão de diferentes conhecimentos. Não se usa o vídeo para apresentar o convencional ou imitar a atmosfera da sala de aula. Fazer isso é subestimar totalmente a sua natureza. O vídeo torna-se um elo fundamental na medida em que surge como um terceiro elemento na relação professor-aluno, constituindo-se como um forte recurso didático audiovisual para a dinamização do ensino e da aprendizagem.

Contudo, é necessário ter consciência de que o vídeo e outras tecnologias educacionais não substituem, em hipótese alguma, o papel do professor. Para realizar um trabalho interdisciplinar, o professor precisa primeiro conhecer o vídeo em sua totalidade e saber quais são as suas reais potencialidades e limitações.

Sendo assim, cabe ao docente assistir atentamente o vídeo educativo escolhido, pontuando o que é mais relevante para sua área ou disciplina, a fim de que possa melhor elaborar seus planejamentos de aulas. É interessante também que o professor construa seu próprio roteiro de trabalho, procurando identificar quais conteúdos curriculares podem ser trabalhados numa perspectiva contextualizada e interdisciplinar, quais habilidades e competências devem ser desenvolvidas nos alunos e quais atividades didáticas poderiam ser realizadas a partir do vídeo.

A título de sugestão, apresentamos a seguir um modelo de ficha-roteiro para observação e análise de vídeos educativos em geral (vide Quadro 1), o qual também pode ser muito útil para o trabalho com o vídeo educativo Nas malhas da geometria:

Quadro 1: Ficha-roteiro de observação e análise de vídeos educativos

para uso escolar.

Ficha-roteiro de observação e análise de vídeos educativos

1a PARTE: Dados de Identificação Geral

Escola/Colégio:

Aluno(a):

Série:

Turma:

Sala no:

Turno/Período:

Data:

Professor(a):

Área(s) de conhecimento:

Disciplina(s): 
2a PARTE: Dados de Identificação Específica

* Ficha técnica

Título:

Origem (brasileira ou estrangeira):

Tempo estimado de duração (em horas, minutos e/ou segundos):

Disponibilidade de acesso (fácil ou difícil de encontrar):

Clima (tenso, divertido, dramático, emocionante, agradável, metafórico, etc.):

Número de cenas exibidas (uma, duas, três, ... , algumas, todas):

Diretor(a) responsável:

Categoria/Gênero (drama, suspense, comédia, desenho animado, aventura, etc.):

Elenco (atores e/ou atrizes):

Distribuidora(s):

Ano de estreia:

Viabilidade:

Sinopse (Resumo):

* Ficha descritiva

Tema:

Ideia central:

Objetivo(s) geral(is) e específico(s):

Assunto(s) abordado(s):

Avaliação crítico-reflexiva (pontos positivos e/ou negativos):

Comentário(s) final(is):

Fonte: Adaptado de Santos (2011).

DOI: Em andamento. 
Nesse processo de análise de vídeos educativos é fundamental que o professor procure aliados, ou seja, outros professores da sua disciplina e de outras áreas (afins ou não) para, após assistirem ao vídeo escolhido, juntos iniciarem a elaboração do planejamento integrado das atividades didáticas a serem desenvolvidas a partir do vídeo educativo (MANDARINO, 2002).

Você já imaginou, por exemplo, se cada professor fizer a exibição do mesmo vídeo para os seus alunos, procurando cada um destacar apenas o que se refere ao conteúdo da sua disciplina? Não seria mais produtivo discutir as possibilidades de trabalho conjunto, programar seções coletivas de professores para estudo, reflexão, debate e, a partir daí, trabalhar de forma interdisciplinar os conteúdos das diferentes disciplinas curriculares?

Essa discussão ajuda a enriquecer o trabalho da equipe de professores, pois permite 0 compartilhamento de experiências e de sugestões visando assegurar o desenvolvimento de atividades teóricas e práticas em todas as áreas/disciplinas. Por isso, a eventual dificuldade de realização de uma determinada atividade didática no cotidiano escolar não a desmerece como proposta. Pelo contrário, serve de desafio na busca de outras possibilidades e, principalmente, de melhores condições para o trabalho com os alunos.

No caso específico do vídeo educativo Nas malhas da geometria, o mesmo pode ser utilizado no todo ou em parte, tanto para motivar os alunos para um tema específico quanto para aprofundar e sistematizar alguns conhecimentos já trabalhados ou não em sala de aula pelo docente. Dizemos isso, porque concordamos com Sá (2000, p.32) ao enfatizar que "a melhor forma de usar um vídeo em sala de aula depende de cada professor e dos objetivos a serem alcançados. Nessa decisão, convém considerar, pois, o 'poder didático' que as imagens podem oferecer".

Antes de exibir o vídeo em sala de aula, é fundamental que o professor aguce a curiosidade e incentive os alunos a assistirem atentamente o filme, informando-os sobre as atividades didáticas que serão posteriormente desenvolvidas. Ao final da exibição fílmica, é importante que o docente não deixe de relacionar com os educandos as situações apresentadas e a experiência do grupo, ou o seu contraste, trazendo a discussão para a realidade cotidiana, em seu tempo e espaço, a fim de que ela adquira significado(s).

O professor pode também exibir o vídeo fazendo algumas pausas para reflexões e debates, ao invés de exibi-lo na sua totalidade, para somente depois iniciar uma discussão coletiva. No caso de optar pelo debate reflexivo em sala de aula, à medida que o vídeo for sendo exibido, sugere-se que o professor elabore um roteiro com questões relativas ao(s) assunto(s) abordado(s) pelo vídeo para assim conduzir as discussões de modo eficaz e eficiente. Todavia, a exibição e discussão do vídeo devem ocorrer, se possível, numa mesma aula, a fim de que não se perca "o fio da meada". Não é muito produtivo exibir o vídeo numa aula e somente dois ou três 
dias depois discutir com os alunos o conteúdo do mesmo. Isso pode provocar desinteresse nos educandos e gerar sérios problemas de indisciplina em sala de aula.

De modo geral, o vídeo educativo Nas malhas da geometria busca demonstrar visualmente a intercomplementaridade de conteúdos curriculares concernentes às disciplinas de Matemática, Artes Plásticas, História, Geografia, Filosofia, Biologia entre outras áreas do saber; uma vez que aborda questões de história da arte, fala sobre ângulos de perspectiva em trabalhos artísticos, mostra os mosaicos do período islâmico, apresenta noções de simetria e regularidade, propõe atividades de desenho artístico e motiva a procurar formas geométricas existentes em animais e plantas.

\subsection{Realização de estudos temáticos específicos de geometria plana}

Nas malhas da geometria pode ajudar a enriquecer a atividade exploratória e investigativa dos alunos do ensino médio em relação ao estudo de geometria plana. Entretanto, se o vídeo apresentasse apenas uma aula de matemática através de gravações ou demonstrações de pessoas manipulando materiais concretos, seu potencial como recurso didático-pedagógico seria limitado e obsoleto. Matemática se aprende fazendo, resolvendo problemas práticos, (re)construindo e desconstruindo conhecimentos e saberes.

Isso significa dizer que os vídeos educativos, especialmente produzidos para uso conjugado com a TV numa determinada disciplina do currículo escolar, devem ser abrangentes e conter informações verídicas referentes ao campo temático em estudo. "A utilização de qualquer vídeo educativo em sala de aula exige planejamento prévio, preparação e sólida proposta pedagógica de ensino por parte do professor, a fim de facilitar a aprendizagem dos educandos" (FERRÉS, 1996, p.32).

No caso específico da área de Matemática, o vídeo Nas malhas da geometria pode ser utilizado, por exemplo, para trabalhar alguns conteúdos do currículo escolar, tais como: simetrias, regularidades, mosaicos, perspectivas, projeções no plano, divisão do plano em malhas (triangular, quadriculada, retangular etc.), formas e ângulos de figuras geométricas entre outros.

Em relação ao tema "mosaicos", em particular, é importante destacar que embora o mesmo não se configure como um conteúdo tradicional no currículo de Matemática, trata-se de um tópico que possibilita ao professor explorar diversos assuntos de geometria, a saber: triângulos, quadriláteros, polígonos regulares, relações angulares, regularidades, formas geométricas bidimensionais entre muitos outros de natureza procedimental (IMENES, 1987).

Para a abordagem do assunto "polígonos regulares", por exemplo, o professor pode propor aos alunos as seguintes questões básicas para reflexão, análise e discussão em classe: Por

DOI: Em andamento. 
que as abelhas constroem seus alvéolos com formato de prismas hexagonais regulares? Por que os ladrilhos e as lajotas mais usadas no campo da construção civil são em forma de quadrados, retângulos ou hexágonos regulares? Por que um ladrilho em forma de pentágono regular não pode ser utilizado para pavimentar uma determinada porção do plano?

Outras indagações dessa natureza podem ser formuladas pelos professores para um melhor desenvolvimento e aprofundamento do assunto abordado. Sugere-se que após a discussão dessas questões, o professor também efetue comentários sobre a contribuição do artista holandês Maurits Cornelis Escher (1898-1972) no campo da geometria (BARBOSA, 1993), apresente aos alunos alguns exemplos de padrões geométricos idealizados por Escher (vide Figura 1) e uma breve fundamentação teórica (texto de informação ou resumo esquemático) sobre a temática em estudo, propondo ainda alguns exercícios práticos que necessitem da aplicação imediata dos conceitos trabalhados.

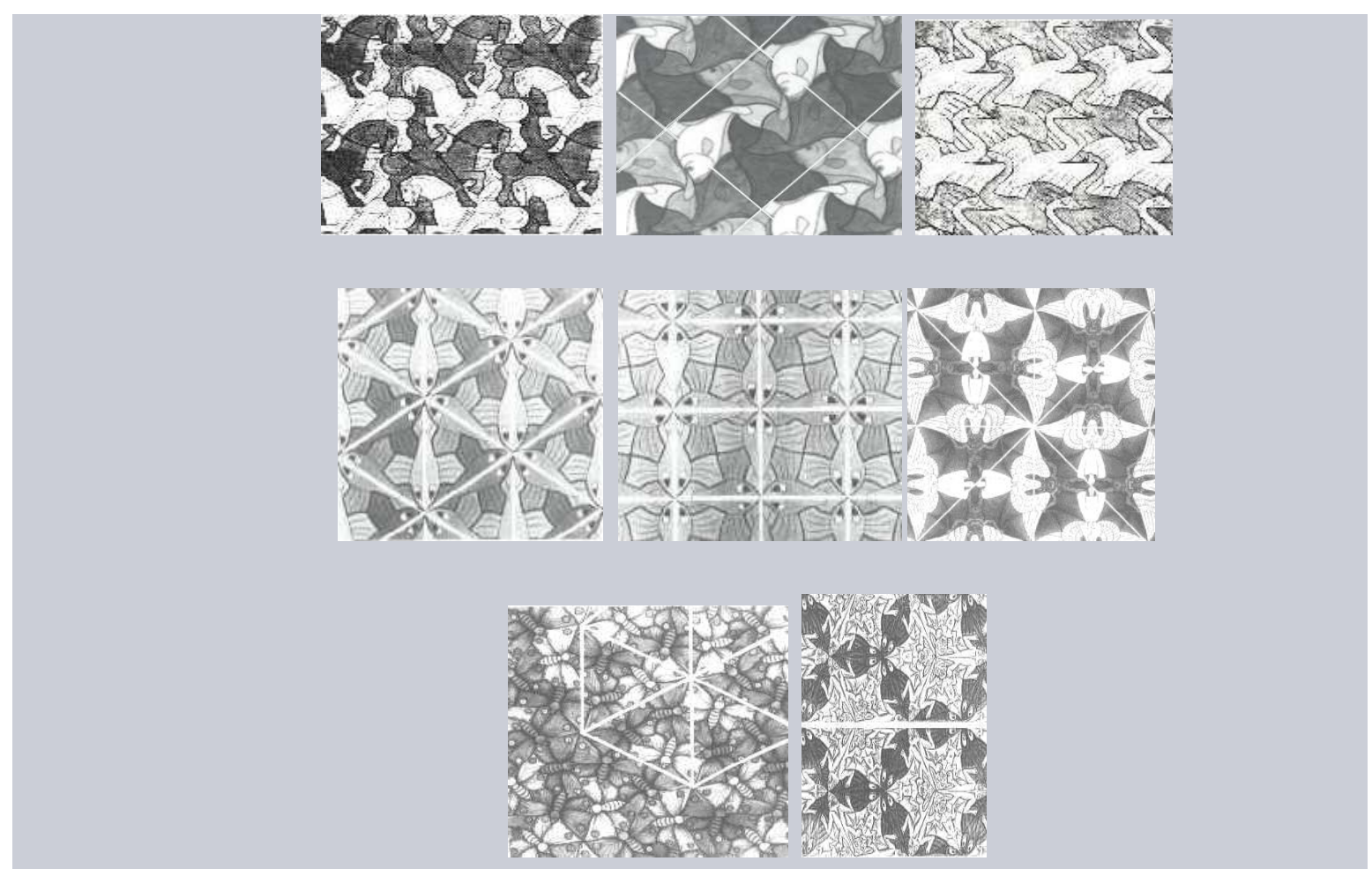

Figura 1: Exemplos de padrões geométricos idealizados por Maurits Cornelis Escher.

Fonte: <http://www.mat.uel.br/geometrica>

Convém salientar que, além das sugestões apresentadas, muitas outras atividades didáticas concernentes ao tema "mosaicos" podem ser propostas pelo professor em sala de aula, pois tudo dependerá da sua criatividade e capacidade em perceber as necessidades e possíveis dificuldades apresentadas pelos educandos em relação à abordagem dessa temática. 0 mais 
importante de todo esse processo é que os alunos tenham consciência de que os mosaicos podem ser facilmente encontrados na pavimentação de calçadas, nos ladrilhos de paredes, na Natureza, em obras de arte e em muitos outros contextos da realidade cotidiana; conforme pode ser observado nas ilustrações abaixo (vide Figuras 2; 3 e 4):

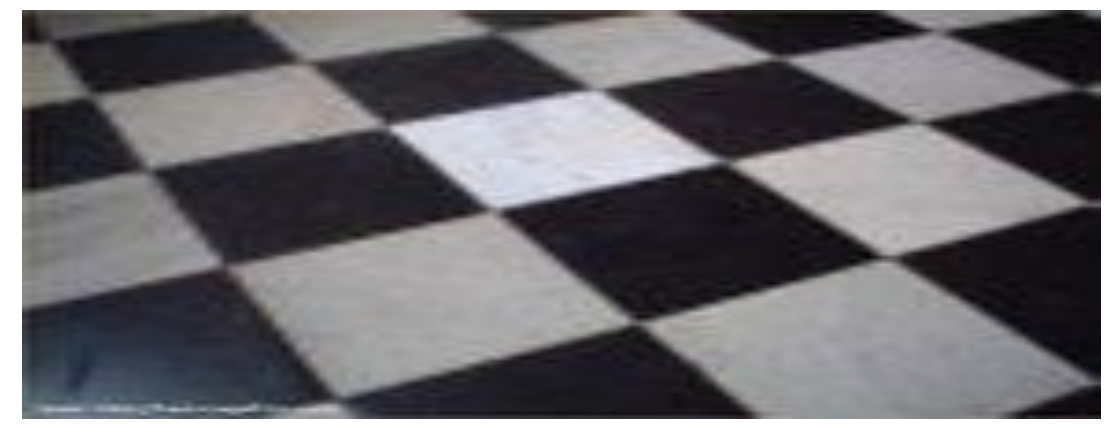

Figura 2: Mosaico - Recobrimento de piso em formato quadrangular Fonte: <http://www.matimage.blogspot.com>

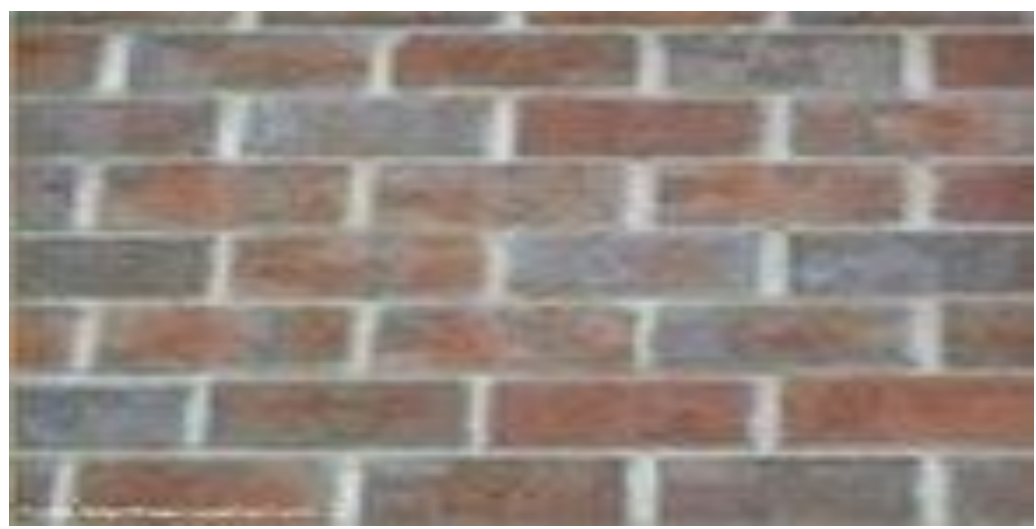

Figura 3: Mosaico - Revestimento de parede em formato retangular. Fonte: <http://www.matimage.blogspot.com>

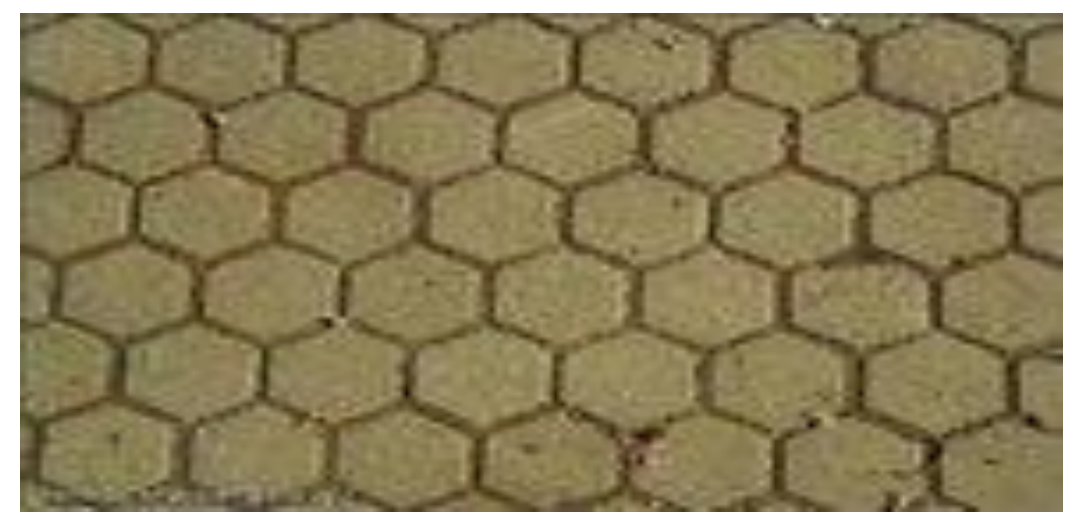

Figura 4: Mosaico - Pavimentação de calçada em formato hexagonal. Fonte: <http://www.matimage.blogspot.com> 
Convém ressaltar que no vídeo educativo Nas malhas da geometria os aspectos técnicos e descritivos que o professor vai explorar e as atividades posteriores a serem realizadas com os alunos irão, naturalmente, variar em função dos objetivos propostos para cada aula e das habilidades e competências já desenvolvidas pelos educandos. Por isso, vale lembrar: ainda que o professor escolha um vídeo apropriado ao(s) conteúdo(s) curricular(es) que pretende abordar, o trabalho não ficará totalmente completo se as atividades didáticas desenvolvidas a partir dele não levarem o aluno a pensar, refletir, relacionar e lançar um olhar crítico sobre aquilo à que assiste.

\subsection{Proposição de atividades didáticas complementares visando à construção do pensamento geométrico}

Dentre os muitos conteúdos curriculares que podem ser trabalhados pelos professores de matemática no ensino médio a partir do vídeo educativo Nas malhas da geometria, vamos exemplificar, a critério de proposição de atividades didáticas complementares, como as "pavimentações do plano" (no vídeo, "malhas") podem ser abordadas em sala de aula, em três momentos distintos, a saber:

\subsubsection{Primeiro momento}

O professor inicia solicitando aos alunos que construam, em folha de papel sulfite, uma malha de triângulos e quadrados (vide Figuras 5 e 6; respectivamente), alertando-os para o fato de que quadrados e triângulos regulares devem ter os lados de mesmo tamanho, isto é, de igual medida de comprimento, e que os quadrados não podem encostar seus lados nos outros quadrados. Eles somente podem se encontrar pelos vértices. O resultado final será, pois, uma malha geométrica composta por triângulos e quadrados regulares (vide modelo apresentado na Figura 7). 


Para desenhar a malha triangular
com o lado do triângulo igual a "D" faça um
feixe de paralelas com distância "A" =
"D"/2 e outro ortogonal com distância
"C" = 0,86660 "D". Unindo os pontos
conforme indicado na ilustração ao lado,
está construída a malha geométrica
triangular (malha W).

Figura 5: Construção de malha geométrica triangular.

Fonte: <http://www.portalradix.com.br>

Marque um feixe de paralelas separadas entre si de uma distância constante igual a "D". Em seguida, marque um outro feixe de paralelas ortogonal à direção anterior, também separadas a uma distância "D". O resultado final será a malha geométrica quadrangular (malha S), cuja ilustração está exposta ao lado.
MALHA $S$

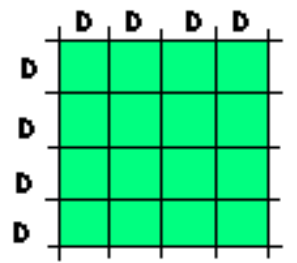

D : 1 unidade

Figura 6: Construção de malha geométrica quadrangular.

Fonte: <http://www.portalradix.com.br>

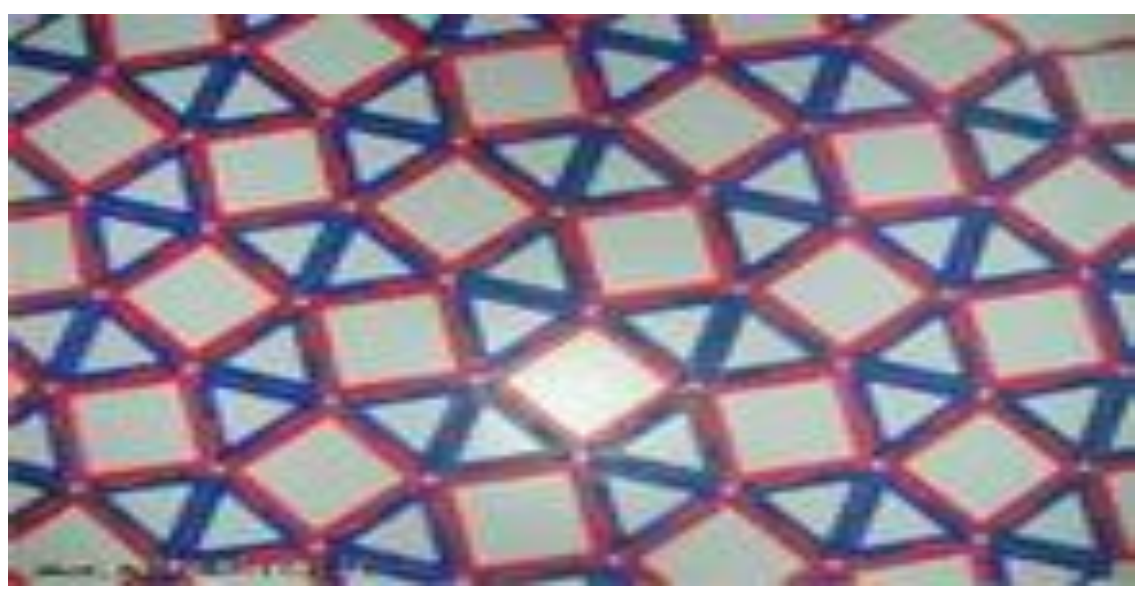

Figura 7: Malha geométrica composta por triângulos e quadrados regulares, em que estes últimos se encontram apenas pelos seus vértices.

Fonte: <http://www.matimage.blogspot.com>

DOI: Em andamento. 
Após esses procedimentos iniciais, é interessante que o professor peça aos alunos que observem as malhas desenhadas pelas crianças no vídeo Nas malhas da geometria, indagando: Elas estão bem desenhadas? É possível visualizar os padrões geométricos formados? Haveria um jeito diferente de construir as malhas?

O fato dos desenhos dos alunos não serem muito precisos, pode ser utilizado pelo professor para explicar a necessidade de rigor geométrico em Matemática. Naturalmente, o grau de rigorosidade a ser mantido numa atividade como essa vai depender do nível de conhecimento intelectual dos educandos. Todavia, um procedimento fácil e não muito rigoroso de ser realizado, mas com precisão maior que os desenhos feitos à mão livre pelas crianças do vídeo, é a utilização de "moldes" dos polígonos que formam a "pavimentação do plano": quadrados e triângulos regulares de mesmo tamanho. Esses "moldes" podem ser os modelos comercializados ou aqueles feitos em papel cartolina.

Outro procedimento de maior precisão a ser efetuado, embora sem muito rigor matemático, é a utilização de régua e transferidor para a construção dos desenhos. Aqui o uso de modelos é extremamente útil para os alunos que não apresentam grande destreza com os instrumentos de desenho geométrico (réguas, esquadros, transferidor, compasso etc.).

Na sequência, o professor pode pedir que cada aluno compare a malha que fez com as de seus colegas de classe, perguntando: Quantos tipos de malha podem ser feitos a partir das instruções iniciais? É possível fazer mais algum tipo? Qual? Como ter absoluta certeza? A resposta a essas questões requer dos alunos a utilização de um método de trabalho e uma argumentação matemática lógica para provar que todas as possibilidades de construção de malha foram esgotadas.

Posto isso, o professor poderá solicitar aos alunos que observem um vértice qualquer na sua malha, questionando: Qual é a configuração dos polígonos colocados ao redor desse ponto? Essa questão explora, pois, um marco de referência talvez ainda não utilizado pelos alunos para observar os padrões geométricos formados, o que os ajudará a ter absoluta certeza de que a malha construída é o único tipo possível a partir das instruções fornecidas inicialmente, visto que ao redor de um ponto qualquer a única configuração que eles conseguirão fazer se os quadrados não puderem encostar seus lados é: triângulo, triângulo, quadrado, triângulo, quadrado (vide Figura 7).

A seguir, pode-se pedir aos alunos que observem no vídeo exibido a "malha" feita pela aluna que está colorindo os triângulos de verde, propondo as seguintes questões: O padrão geométrico da aluna é igual ao da malha que você fez? Ele é uma outra possibilidade? Ou não é possível? Nesse sentido, as "malhas" construídas pela aluna no vídeo podem ser pensadas também como "pavimentações do plano", principalmente porque as regiões interiores às linhas 
poligonais formadas foram coloridas, dando mais a impressão de uma "cobertura" do plano que de "malha" ou "rede" de segmentos de reta.

Os alunos podem responder a essas perguntas tentando reproduzir, com o material selecionado para a aula (moldes, polígonos regulares, régua e transferidor), a figura feita pelas crianças do vídeo Nas malhas da geometria. Ou ainda: os alunos também podem basear suas respostas na atividade anterior, na qual procuraram verificar todas as possibilidades de construção de malhas obedecendo às instruções iniciais dadas pelo professor. Assim, será reforçada a necessidade de precisão, seja no simples desenho da malha, seja em uma construção mais formal.

Outras atividades semelhantes também podem ser desenvolvidas a partir do vídeo supracitado, mudando algumas de suas instruções, como por exemplo: ainda utilizando apenas quadrados e triângulos regulares de mesmo lado, o professor pode solicitar aos alunos que construam outras malhas, de forma que agora os quadrados possam encostar seus lados (vide Figura 8).

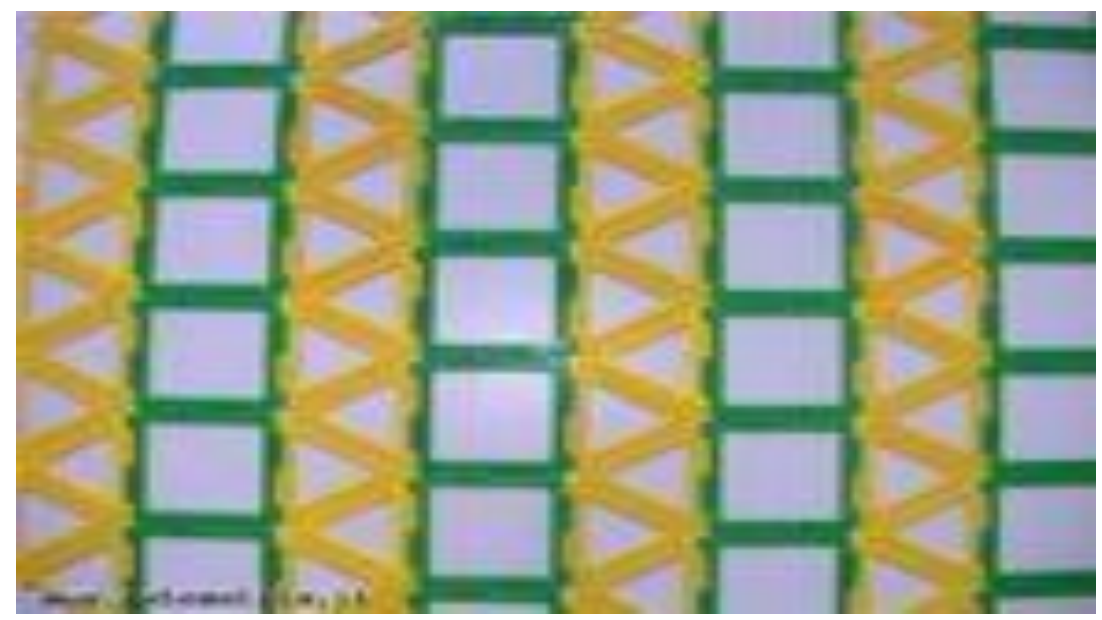

Figura 8: Malha geométrica composta por triângulos e quadrados regulares, em que estes últimos encostam seus lados.

Fonte: <http://www.matimage.blogspot.com>

A partir dessa construção, convém indagar: Quantos tipos de configurações podem ser encontrados ao redor de um ponto? É possível construir outras malhas combinando essas configurações? E se agora pudermos usar, além dos quadrados e triângulos, hexágonos regulares com lados iguais aos dos quadrados e triângulos? Quantos tipos de configurações podem ser obtidos dessa forma? Que malhas podemos construir combinando essas configurações? E se utilizarmos apenas quadrados e octógonos regulares de mesmo lado? Triângulos e dodecágonos? Quadrados, hexágonos e dodecágonos? Triângulos e hexágonos? Convém perceber que a 
dedução das medidas dos ângulos e lados envolvidos na "pavimentação do plano" já é uma atividade de caráter bastante diferente do simples desenho, pois permite o estudo de propriedades dos polígonos e desenvolve competências em dedução lógica.

De acordo com Barbosa (1993) um jeito bastante fácil de determinar se uma configuração ao redor de um ponto é possível ou não, é verificar se a soma dos ângulos ao redor do ponto é igual a 360․ Para o autor, o controle de 360 mostra também quanto os limites de nossa acuidade visual e dos nossos materiais de desenho nos levam a crer que determinadas figuras se encaixam perfeitamente, quando na verdade elas não se encaixam; pois ao tentar colocar, por exemplo, um pentágono, um hexágono e um octógono regular ao redor de um ponto, temos a

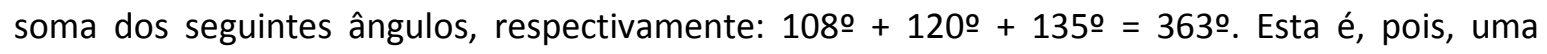
diferença visual quase imperceptível, mas que não permite uma perfeita "pavimentação do plano".

Constatações como essa numa aula de geometria plana ajudam, sobremaneira, os alunos a adquirir uma atitude crítico-reflexiva em relação ao que assistiram no vídeo Nas malhas da geometria: no caso, o método utilizado para a construção das "malhas".

\subsubsection{Segundo momento}

O professor deverá pedir aos alunos que escolham, aleatoriamente, uma caneta de cor diferente para marcar um ponto no centro de cada quadrado e de cada triângulo da malha construída, no intuito de em seguida ligar esses pontos com a caneta traçando somente linhas retas, as quais não poderão passar por nenhum vértice das figuras.

Esse processo consiste em encontrar o padrão geométrico dual para diferenciá-lo do padrão inicial. Dessa forma, o professor pode ir além do vídeo, perguntando aos alunos: Que polígono aparece na nova malha? Ele é regular ou irregular? Possui algum eixo de simetria? Quantos? Qual é a medida de seus ângulos internos e externos?

Em seguida, pode-se propor também que se repita a atividade descrita anteriormente para os pentágonos irregulares encontrados, ou seja, que se desenhe o padrão geométrico dual para diferenciá-lo do padrão de pentágonos.

O objetivo disso é fazer com que os alunos assinalem com um ponto o centro de cada pentágono para em seguida, com uma segunda caneta de cor diferente, ligar esses pontos fazendo somente linhas retas. O resultado obtido pode deixar os alunos surpresos, visto que os dois padrões geométricos - o de quadrados e triângulos regulares e o de pentágonos irregulares são duais-recíprocos, isto é, um é o dual do outro.

A título de curiosidade, vale destacar que as malhas geométricas denominadas "duais" são aquelas que têm por "nós" os centros dos polígonos definidos pelas malhas semiregulares. As 
malhas regulares são duais de si mesmas, ou seja, a malha triangular é dual da hexagonal e viceversa (vide Figura 9), assim como a malha quadrangular é dual dela própria (vide Figura 10); por exemplo.
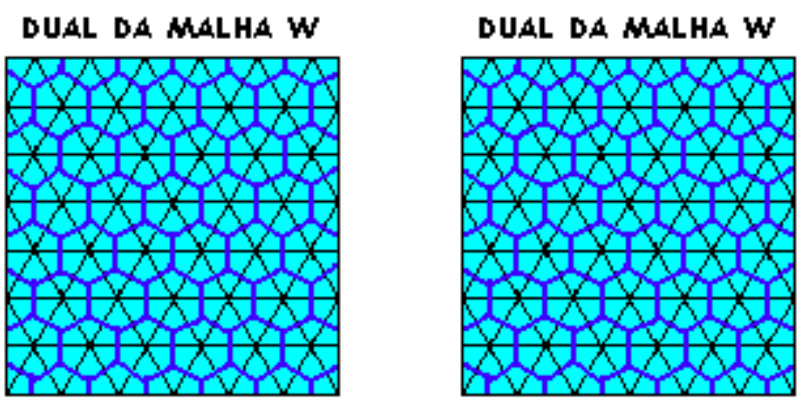

Figura 9: Malha triangular é dual da hexagonal (e vice-versa).

Fonte: <http://www.portalradix.com.br>

DUAL DA

MALHA S

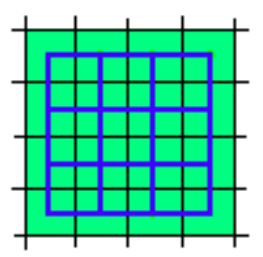

Figura 10: Malha quadrangular é dual dela própria.

Fonte: <http://www.portalradix.com.br>

\subsubsection{Terceiro momento}

O professor deve solicitar aos alunos que com uma terceira caneta de cor diferente, marquem o meio dos lados dos quadrados e dos triângulos e liguem esses pontos traçando somente linhas retas. $O$ resultado obtido será uma terceira malha construída com essa terceira cor de caneta. É interessante que os alunos percebam nessa atividade que é possível ficar sempre dividindo e ligando os pontos, e que dessa forma se podem construir muitas outras "malhas" diferentes.

Mais de uma vez o professor pode realizar essa atividade com os alunos, haja vista que o vídeo educativo Nas malhas da geometria não deixa explícito o resultado final a ser alcançado. Por isso, há possibilidade do professor ir muito mais além do vídeo, indagando aos alunos: Que 
polígonos aparecem na nova malha? Eles são regulares? Os irregulares possuem algum eixo de simetria? Qual? Quantos? Qual é a medida de seus ângulos internos e externos?

Além dessas indagações, outras ainda também podem ser formuladas pelo professor. Tudo dependerá dos objetivos que se pretende alcançar com a abordagem do tema em estudo. Nesse momento, nada impede que teoria e outras atividades práticas similares a respeito de "pavimentações do plano" possam ser trabalhadas pelo professor em sala de aula, caso seja necessário.

\section{Considerações finais}

Sendo o ser humano eminentemente visual, onde a visão tem papel preponderante em comparação aos demais sentidos humanos, torna-se conveniente, de acordo com Fonseca et al (2001) e Santos (2011), que os professores de matemática utilizem, sempre que possível, dentre outros recursos didático-pedagógicos existentes, vídeos educativos em aulas de geometria (plana, espacial, analítica etc.) com o objetivo de levar os alunos a desenvolver o pensamento geométrico. Dizemos isso, porque a aprendizagem de geometria em geral implica colocar os educandos em ação, fazendo relações entre as coisas, observando, explorando, manipulando, representando, classificando, construindo e justificando a partir do que os cerca e das situaçõesproblema do cotidiano (DOMINGUES, 1994).

Não pretendemos neste artigo esgotar as possibilidades de exploração didática do vídeo educativo Nas malhas da geometria, nem tampouco oferecer "receitas pedagógicas" prontas e acabadas. Buscamos apenas sugerir algumas propostas de atividades didáticas que podem ser utilizadas pelos professores de matemática em sala de aula, a fim de tornar a aprendizagem matemática dos alunos do ensino médio substancialmente mais rica e significativa.

Esperamos, assim, que professores de matemática e educadores matemáticos possam aproveitar ao máximo as sugestões didáticas aqui apresentadas, no sentido de desmistificar tabus e estereótipos que gravitam em torno do ensino e da aprendizagem da geometria plana na escola; bem como desenvolver ideias novas e criativas de trabalho, tendo a consciência de que nenhum recurso didático-pedagógico jamais poderá ou deverá substituir o papel mediador do professor em sala de aula.

Vídeos educativos e outras tecnologias midiáticas são, portanto, apenas meios auxiliares à conquista de uma Educação Matemática de qualidade; cuja origem e evolução está diretamente atrelada às relações umbilicais estabelecidas entre a Matemática presente na escola da vida e na vida na escola. 


\section{Referências}

BARBOSA, R. M. Descobrindo padrões em mosaicos. São Paulo: Atual, 1993.

BRASIL. Ministério da Educação. Secretaria de Educação a Distância. Cadernos da TV Escola: guia de vídeos didáticos. Brasília: MEC, 2000.

D'AMBRÓSIO, U. Da realidade à ação: reflexões sobre educação e matemática. 4.ed. São Paulo: Summus, 1986.

DOMINGUES, H. H. Aprendendo e ensinando geometria. São Paulo: Atual, 1994.

FERRÉS, J. Vídeo e educação. 2.ed. Porto Alegre: Artes Médicas, 1996.

FONSECA, M. C. F. R. et al. O ensino de geometria na escola fundamental: três questões para a formação do professor dos ciclos iniciais. Belo Horizonte: Autêntica, 2001.

IMENES, L. M. P. Geometria dos mosaicos. São Paulo: Editora Scipione, 1987. (Coleção Vivendo a Matemática).

MANDARINO, M. C. F. Organizando o trabalho com vídeo em sala de aula. In: Revista de Ciências Humanas. Rio de Janeiro: Editora FRM, ano 11, n.1, p.1-11, 2002.

SÁ, A. L. A televisão e o vídeo na sala de aula. São Paulo: Editora Martins Fontes, 2000.

SANTOS, M. P. Recursos didático-pedagógicos na educação matemática escolar: uma abordagem teórico-prática. Rio de Janeiro: Ciência Moderna Ltda, 2011.

MARCOS PEREIRA DOS SANTOS - Doutorando em Educação Religiosa, linha de pesquisa "Cultura Geral”, pela Faculdade de Educação Teológica Fatefama (FATEFAMA). Escritor, poeta, cronista, articulista e pesquisador da área educacional. Membro correspondente da Academia de Letras de Teófilo Otoni (ALTO/MG). Professor adjunto da Faculdade Sagrada Família (FASF), junto a cursos de graduação (bacharelado/licenciatura) e pós-graduação lato sensu, em Ponta Grossa (PR). Email: mestrepedagogo@yahoo.com.br

DOI: Em andamento. 